\title{
Oxygen-18 Isotope Effect in the Reaction of Oxygen with Copper
}

\author{
RICHARD B. BERNSTEIN \\ Department of Chemistry, University of Michigan, Ann Arbor, Michigan
}

(Received December 13, 1954)

\begin{abstract}
The fractionation of oxygen-18 in the reaction of copper with oxygen of natural isotopic composition has been measured over the temperature range $68-256^{\circ} \mathrm{C}$. The oxide films (estimated thicknesses varying from $150-2500 \mathrm{~A}$ ) were removed for $\mathrm{O}^{18}$ assay by treatment with hydrogen at $350^{\circ} \mathrm{C}$. Using the $\mathrm{CO}_{2}$ equilibration technique, the $\mathrm{O}^{18} / \mathrm{O}^{16}$ ratios for the resulting water samples were determined mass spectrometrically and compared with the ratio for a reference sample of water prepared from the original oxygen gas.

The direction of the fractionation indicated that $\mathrm{O}_{2}{ }^{16}$ reacts preferentially compared to $\mathrm{O}^{16} \mathrm{O}^{18}$. The isotope effect appeared to be independent of the oxygen pressure over the limited range studied $(2-25 \mathrm{~cm} \mathrm{Hg})$. The magnitude of the fractionation factor was $2.0 \%$ at $150^{\circ} \mathrm{C}$, with a small negative temperature coefficient. From this it was possible to estimate a value of $\Delta E_{\mathrm{act}}=17 \mathrm{cal} / \mathrm{mole}$, which may be compared with the calculated isotopic zero-point energy difference of $64 \mathrm{cal} / \mathrm{mole}$. The theoretical implications of the experimental results are discussed.
\end{abstract}

\section{INTRODUCTION}

A GREAT deal of experimental work on the kinetics of the reaction of oxygen with metals has appeared in the literature. A review of the experimental and theoretical aspects of this subject appears in the recent book by Kubaschewski and Hopkins. ${ }^{1}$ Tylecote $^{2}$ has summarized the voluminous literature on the reaction of oxygen with copper.

Depending upon the extent of oxide film formation and the temperature, it appears that at least three oxidation mechanisms and rate laws apply to the oxidation of copper. In the case of low temperatures and very thin films (less than about $25 \mathrm{~A}$ ) the logarithmic law is obeyed ${ }^{3}$ as predicted from the Mott-Cabrera theory. ${ }^{4,5}$ At higher temperatures and for films of intermediate thickness (up to about $10^{4} \mathrm{~A}$ ) the cubic law is observed, ${ }^{3,6}$ as discussed by Cabrera. ${ }^{7}$ For thicker films the familiar parabolic law describes the kinetics, as explained by the Wagner theory. ${ }^{8}$

It was thought that new and independent information bearing on the mechanism of the reaction of oxygen with metals could be obtained by a study of the oxygen isotope effect. For example, in the thick film region it is generally agreed that the rate-determining step is the diffusion of cuprous ions through the cuprous oxide lattice. At moderate pressures the reaction rate depends only very slightly upon the pressure ${ }^{9}$ so that the surface may be considered to be saturated with an adsorbed layer of oxygen. Any $\mathrm{O}^{18}$ fractionation which might be observed in the course of the oxidation would then be

${ }^{1}$ O. Kubaschewski and B. E. Hopkins, Oxidation of Metals and Alloys (Academic Press, Inc., New York, 1953).

2 R. F. Tylecote, J. Inst. Metals 78, 259 (1950).

3 T. N. Rhodin, J. Am. Chem. Soc. 72, 5102 (1950).

${ }^{4}$ N. F. Mott, Trans. Faraday Soc. 43, 429 (1947).

5 N. Cabrera and N. F. Mott, Repts. Progr. Phys. 12, 163 (1948-1949).

${ }^{6}$ W. E. Campbell and U. B. Thomas, Trans. Electrochem. Soc. 91, 623 (1947).

${ }^{7}$ N. Cabrera, Phil. Mag. 40, 175 (1949).

${ }^{8}$ C. Wagner, Z. physik. Chem. B21, 25 (1933).

9 C. UWagner and K. Grunewald, Z. physik. Chem. B40, 455 (1938). associated with an isotope exchange equilibrium between gaseous oxygen and adsorbed atomic or molecular oxygen. In the case of adsorbed atoms this exchange would favor the concentration of the light isotope in the adsorbed layer; for adsorbed molecular oxygen the reverse would be expected. A possible rate-limiting step under certain conditions might involve an irreversible process such as the rupture of the $\mathrm{O}-\mathrm{O}$ bond; for example, the reaction $4 e^{-}+\mathrm{O}_{2} \rightarrow 2 \mathrm{O}^{=}$. Here the effect would be such that $\mathrm{O}^{16}$ would tend to be concentrated in the oxide.

Dole and Lane ${ }^{10}$ have reported some preliminary results on the fractionation of $\mathrm{O}^{18}$ during the chemisorption of oxygen on copper and steel at room temperature. The residual oxygen remaining unreacted after chemisorption was analyzed and found to be depleted in $\mathrm{O}^{16}$, corresponding to a fractionation factor of about 1.05 for copper and 1.025 for steel.

The present report deals with a study of the $\mathrm{O}^{18}$ fractionation in the reaction of oxygen with copper for the case of oxide films of intermediate thickness. The method involves removal of the oxide film, measurement of its $\mathrm{O}^{18} / \mathrm{O}^{16}$ ratio and comparison with the isotope ratio for the gaseous oxygen.

\section{EXPERIMENTAL \\ Materials}

The copper samples were prepared by hydrogen reduction of short lengths of $\mathrm{CuO}$ wire, Reagent Grade (General Chemical Company), stated to contain less than $0.01 \%$ of impurities. Samples ranging from 1-12 g were used. They were normally contained in small Pyrex boats which were perforated to allow gas circulation.

The oxygen used for most of the experiments was commercial tank oxygen (Bird Gas Division, Liquid Carbonic Corporation) purified by passage through silica gel, ascarite, $\mathrm{P}_{2} \mathrm{O}_{5}$, and a cold trap at $-78^{\circ} \mathrm{C}$. Mass spectral analysis showed it to contain only nitro-

\footnotetext{
${ }^{10}$ M. Dole and G. A. Lane, J. Chem. Phys. 22, 949 (1954).
} 
gen and argon (totalling approximately $0.5 \%$ ). A reference sample of some twenty grams of water was prepared from this oxygen by a nearly stoichiometric reaction with oxygen-free hydrogen at about $1000^{\circ} \mathrm{C}$ over a platinum gauze catalyst. ${ }^{11}$ For certain check experiments oxygen was prepared by the electrolysis of a $40 \% \mathrm{NaOH}$ solution using nickel electrodes. The electrolytic oxygen was purified by passage through a bubbler tube of $95 \% \mathrm{H}_{2} \mathrm{SO}_{4}$ followed by ascarite, silica gel, and anhydrous $\mathrm{CaSO}_{4}$. Mass spectrometric analysis showed it to be of greater than $99.9 \%$ purity.

Hydrogen from a commercial cylinder was purified by passage through a "De-Oxo" catalyst tube (J. T. Baker Chemical Company) followed by ascarite, silica gel, $\mathrm{P}_{2} \mathrm{O}_{5}$, and a cold trap at $-195^{\circ} \mathrm{C}$.

Carbon dioxide was obtained from two sources: either dry ice or a commercial tank (Matheson "Bone-Dry" grade). After passing through a train containing silica gel and $\mathrm{P}_{2} \mathrm{O}_{5}$, the gas was subjected to a trap-to-trap distillation from $-78^{\circ}$ to $-195^{\circ} \mathrm{C}$. The mass spectrum of the resulting $\mathrm{CO}_{2}$ revealed no significant impurities.

\section{Apparatus, Procedure, and Analytical Method}

The experiments were carried out in a conventional high vacuum apparatus. The Pyrex reaction vessel was enclosed in a specially constructed electric furnace provided with transparent Vycor walls, which permitted visual observation of the surface of the copper during the course of its oxidation. The extent of oxidation was monitored by means of a differential oil manometer as well as a mercury manometer. The decrease in oxygen pressure at constant temperature and at essentially constant volume could be related to the oxygen uptake by the copper. In certain experiments the weight increase of the metal sample was measured as a check.

In a typical experiment the copper sample was evacuated to $10^{-4} \mathrm{~mm} \mathrm{Hg}$, then heated (while continuously pumping) to the desired temperature, controlled to $\pm 1^{\circ} \mathrm{C}$. A calibrated Chromel-Alumel thermocouple was located directly on the outer wall of the reaction vessel to indicate the temperature of the sample. Oxygen was admitted and the rate of oxygen consumption followed manometrically. After reaction for a definite time the excess oxygen was pumped away. Hydrogen was then admitted and the sample was heated to $350^{\circ} \mathrm{C}$ for approximately 10 minutes (which was found to be sufficient to reduce the oxide quantitatively). The water was distilled (in vacuo) into a special weighing ampoule provided with a stopcock and $\$$ joint. It was thus possible to measure the quantity of water formed in each run. In most of the experiments the water samples ranged from $5-25 \mathrm{mg}$, which were determined to $\pm 0.1 \mathrm{mg}$.

The water sample was then distilled into an equilibration $^{12}$ tube of about $10 \mathrm{cc}$ volume. A small quantity

${ }^{11}$ Anderson, Halford, and Bates, J. Chem. Phys. 2, 342 (1934).

${ }^{12} \mathrm{M}$. Cohn and H. C. Urey, J. Am. Chem. Soc. 60, 679 (1938); J. P. Hunt and H. Taube, J. Chem. Phys. 19, 602 (1951). of $\mathrm{CO}_{2}$ was metered out from a standard volume and distilled into the equilibration tube. In order to minimize the correction for isotopic dilution the molar ratio of $\mathrm{CO}_{2}$ to $\mathrm{H}_{2} \mathrm{O}$ was usually kept less than 0.1 .

After allowing the $\mathrm{CO}_{2}-\mathrm{H}_{2} \mathrm{O}$ equilibration to proceed at room temperature for 2-5 days, the $\mathrm{CO}_{2}$ was distilled from the equilibration tube at $-78^{\circ} \mathrm{C}$ into a sampling tube at $-195^{\circ} \mathrm{C}{ }^{*}$ In the case of the reference water, large samples ( $c a 250 \mathrm{mg}$ ) were used; since the $\mathrm{CO}_{2} / \mathrm{H}_{2} \mathrm{O}$ ratio was of the order of 0.005 no dilution correction was required.

An isotope-ratio mass spectrometer (Nier design) was used to determine the $\mathrm{C}^{12} \mathrm{O}^{16} \mathrm{O}^{18} / \mathrm{C}^{12} \mathrm{O}_{2}{ }^{16} \mathrm{ratio}(\mathrm{m} / \mathrm{e} 46 / 44)$ for $\mathrm{CO}_{2}$ from the reference water, $\mathrm{CO}_{2}$ from the "unknown" water sample, and $\mathrm{CO}_{2}$ from the storage bulb. From these ratios and the known value of the $\mathrm{CO}_{2} / \mathrm{H}_{2} \mathrm{O}$ molar ratio the isotopic enrichment may be calculated.

The exact expression for the dilution correction given by Dostrovsky and Klein ${ }^{13}$ may be considerably simplified for the "tracer" case to give the following very good approximation:

$$
N_{0}=\frac{r_{e}}{K}+\frac{b}{a}\left(r_{e}-r_{0}\right),
$$

where $N_{0}=$ atom fraction of $\mathrm{O}^{18}$ in "unknown" $\mathrm{H}_{2} \mathrm{O}$ before equilibration; $r_{0}=46 / 44$ ratio for initial $\mathrm{CO}_{2}$ (storage bulb), $r_{e}=46 / 44$ ratio for equilibrated $\mathrm{CO}_{2} ; b / a$ is the molar ratio, $\left(\mathrm{CO}_{2}\right) /\left(\mathrm{H}_{2} \mathrm{O}\right) ; K$ is the isotope exchange equilibrium constant $=2.08$ at room temperature. ${ }^{12}$

To establish confidence in the $\mathrm{O}^{18}$ analytical technique several samples of $\mathrm{O}^{18}$ - enriched water (Stuart Oxygen Company, stated to contain $1.4 \% \mathrm{O}^{18}$ ) were assayed and compared with distilled tap water. Normalizing these values, assuming $0.200 \% \mathrm{O}^{18}$ in distilled $\mathrm{H}_{2} \mathrm{O}$, three independent determinations gave $1.42,1.44$, and $1.42 \%$ $\mathrm{O}^{18}$ for the enriched water.

The separation factor in the reaction of oxygen with copper is defined:

$$
S=\frac{\left[\left(\mathrm{O}^{18}\right) /\left(\mathrm{O}^{16}\right)\right]_{\text {oxide film }}}{\left[\left(\mathrm{O}^{18}\right) /\left(\mathrm{O}^{16}\right)\right]_{\text {oxygen gas }}} .
$$

Because of the negligible dilution correction for the reference water, Eq. (2) becomes:

$$
S=\frac{\frac{r_{m}}{K}+-\left(r_{m}-r_{0}\right)}{\frac{r_{g}}{K}},
$$

* At the suggestion of a referee, certain check experiments were performed which indicated that when tank $\mathrm{CO}_{2}$ was equilibrated with distilled tap water and separated using the procedure described, the $\mathrm{O}^{18} / \mathrm{O}^{16}$ ratio of the $\mathrm{CO}_{2}$ showed an increase of about $1 \%$. This effect introduces only a very slight error in the calculated fractionation factors, which involve essentially the ratio of the $\mathrm{O}^{18} / \mathrm{O}^{16}$ ratios for $\mathrm{CO}_{2}$ equilibrated with the unknown water sample compared to $\mathrm{CO}_{2}$ equilibrated with the reference water sample.

${ }^{13}$ I. Dostrovsky and F. S. Klein, Anal. Chem. 24, 414 (1952). 
where $r_{m}=46 / 44$ ratio for $\mathrm{CO}_{2}$ after equilibration with "unknown" water from the metal oxide, and $r_{g}=46 / 44$ ratio for $\mathrm{CO}_{2}$ after equilibration with reference water prepared from oxygen gas. Defining the $\mathrm{O}^{16}$ enrichment

$$
\epsilon \equiv 1-S \text {, }
$$

one obtains the expression:

$$
\epsilon=\frac{r_{g}-r_{m}}{r_{g}}-2.08-\frac{b\left(r_{m}-r_{0}\right)}{a} .
$$

Equation (5) was used in all cases to calculate the enrichment factor from the four measured quantities $r_{g}, r_{m}, r_{0}$, and $b / a$.

In the course of this work a large number of intercomparisons of various isotope ratios were obtained; some of these results are summarized here. All values are normalized to the reference oxygen as standard.

A. Percentage difference, based on $46 / 44$ ratios, corrected for $\mathrm{CO}_{2}$ dilution effect.

1. Reference $\mathrm{H}_{2} \mathrm{O}$ from standard $\mathrm{O}_{2} \quad 0.00$ (assumed)

2. Distilled tap water $\quad-2.2 \pm 0.2$

B. Percentage difference, based on $34 / 32$ ratios.

1. Reference $\mathrm{O}_{2}$ (purified; tank No. 1)

2. $\mathrm{O}_{2}$ (tank No. 2, Matheson)

3. $\mathrm{O}_{2}$ (purified; tank No. 3, Bird)

4. $\mathrm{O}_{2}$, electrolytic (av of 4 analyses for 4 different batches)

0.00 (assumed) $0.00 \pm 0.05$ $0.00 \pm 0.05$ $-3.9 \pm 0.15$

From the results of $\mathrm{B} 1,2$, and 3 it appears that there is no appreciable isotopic difference among the different tanks of oxygen. Experiments have also shown that the $34 / 32$ ratios for tank oxygen and atmospheric oxygen differ by less than $0.2 \%$. Thus the result A 2 is a measure of the so-called Dole effect, ${ }^{14}$ i.e., the anomalous difference of $2.5 \%$ in the $\mathrm{O}^{18}$ ratio for atmospheric oxygen compared with oxygen from lake water. $\dagger$

The $\mathrm{O}^{18}$ depletion of the electrolytic oxygen (B 4) was somewhat greater than anticipated. On the basis of the electrolytic fractionation, about $1 \%,{ }^{15}$ and the Dole effect, above, one would estimate a maximum depletion of about $3.5 \%$, compared with the observed value of $3.9 \pm 0.15 \%$. This difference may not be serious, however, in view of the large range of values reported for the electrolytic fractionation factor, from 1.008 to $1.035,{ }^{16}$ and its corresponding uncertainty.

The electrolytic oxygen served an important function in checking the direction and magnitude of the isotope effect in the oxygen-copper reaction, as it was initially depleted in $\mathrm{O}^{18}$ far below the level of either atmospheric

${ }^{14}$ M. Dole, J. Am. Chem. Soc. 57, 2731 (1935); Chem. Revs. 51, 263 (1952)

$\dagger$ Note added in proof. $-2.2 \pm 0.2 \%$ is outside the range of values commonly reported for the Dole effect $(2.5-2.8 \%)$, suggesting that fractionation might have occurred in the preparation of the reference water. If so, all fractionation factors, $\alpha$, would be low by $0.3-0.6 \%$. Experiments to check this point are now in progress.

${ }^{15}$ H. L. Johnston, J. Am. Chem. Soc. 57, 484 (1935); Selwood. Taylor, Hipple, and Bleakney, ibid. 57, 642 (1935); M. Dole, J, Chem. Phys. 4, 268 (1936)

${ }^{16}$ I. Kirshenbaum, Physical Properties and Analysis of Heavy Water (McGraw-Hill Company, Inc., New York, 1951), p. 243. oxygen, water, or ordinary carbon dioxide. Thus any leak or contamination would tend to increase the $\mathrm{O}^{18} / \mathrm{O}^{16}$ ratio. Since in the reaction with copper the $\mathrm{O}^{16}$ was found to concentrate in the oxide, the water obtained from the oxide should be further depleted in $\mathrm{O}^{18}$. Experiments with the electrolytic oxygen therefore constituted a severe test of the validity of the experimental procedures.

The enrichments calculated according to Eq. (5) require small corrections to bring all data to the common basis of infinitesimal extent of reaction. The fraction of substrate (oxygen) consumed, represented by $f=\Delta P_{t} / P_{0}$, (where $P_{0}=$ initial oxygen pressure and $\Delta P_{t}=$ total pressure decrement in the course of the reaction) was usually less than 0.1. The standard logarithmic correction formula was employed. ${ }^{17}$ For $f<0.1$ it was convenient to use the simplified formula:

$$
\epsilon_{0}=\epsilon(1+f / 2) \text {. }
$$

The corrected fractionation factor, $\alpha$, is then defined:

$$
\alpha \equiv 1+\epsilon_{0} .
$$

\section{RESULTS}

Certain preliminary experiments were carried out at $337^{\circ}$ and $377^{\circ} \mathrm{C}$ using copper foil of known geometrical area. The total amount of oxygen reacted was, however, insufficient for isotopic analysis (for which a minimum of $3 \mathrm{mg}$ of water is desirable), due to the small area of the sample. The oxidation followed the parabolic law after the first few minutes and the rate constants agreed (within a factor of 2) with the values calculated using the constants of the Arrhenius equation given in reference 1, p. 163. Other experiments with the high surface area copper wire over the temperature range $303-387^{\circ} \mathrm{C}$ also followed the parabolic equation. From these data it was possible to estimate the extent of available surface and thus the specific surface area, which was found to be about $500 \mathrm{~cm}^{2} / \mathrm{g}$. Due to the difficulty in reproducibly reducing and annealing the specimens it was not possible to replicate the rate constants to better than a factor of 2. This difficulty was first pointed out by Dunn ${ }^{18}$ in connection with his studies with active copper prepared by reduction of the oxide. It is possible therefore that the specific surface area varied from run to run by as much as a factor of two. However, assuming a constant value of $500 \mathrm{~cm}^{2} / \mathrm{g}$, the estimated oxide film thickness corresponding to a given weight of oxygen reacted was calculated, using the method of Vernon..$^{19}$ Clearly these values are only indicative of the order of magnitude of the film thickness for any given run. Table I summarizes the reaction conditions and gross observations for all the experiments for which valid isotopic assays were carried out.

${ }^{17}$ W. G. Henderson, Jr., and R. B. Bernstein, J. Am. Chem. Soc. 76, 5344 (1954); Friedman, Bernstein, and Gunning, J. Chem. Phys. 23, 111 (1955)

${ }_{18}^{18}$ J. S. Dunn, Proc. Roy. Soc. (London) A111, 210 (1926)

${ }_{19} \mathrm{~W}$. H. Vernon, J. Chem. Soc. 1926, 2273. 
TABLE I. Summary of reaction data.

\begin{tabular}{|c|c|c|c|c|c|c|c|}
\hline $\begin{array}{l}\text { Run } \\
\text { no. }\end{array}$ & $\begin{array}{l}\text { Temp. } \\
\left({ }^{\circ} \mathrm{C}\right)\end{array}$ & $\begin{array}{c}\text { Oxygen } \\
\text { pressure } \\
P_{0} \\
\text { (cm Hg) }\end{array}$ & $\mathrm{Wt}_{(\mathrm{g})} \mathrm{Cu}$ & $\begin{array}{l}\text { Wt.s of } \\
\mathrm{O}_{2} \text { re- } \\
\text { acted } \\
\text { (mg) }\end{array}$ & $\begin{array}{l}\text { Time } \\
(\min )\end{array}$ & $\begin{array}{r}\text { Est.b } \\
\text { oxide } \\
\text { thick- } \\
\text { ness (A) }\end{array}$ & $\begin{array}{l}\text { Final appearance } \\
\text { of oxide surface }\end{array}$ \\
\hline 11 & 203 & 18.0 & 2.185 & 13.0 & 55 & 1400 & Black \\
\hline 12 & 201 & 1.9 & 2.185 & 11.4 & 110 & 1200 & Black \\
\hline 13 & 155 & 16.3 & 2.185 & 3.4 & 355 & 360 & Brown-black \\
\hline 14 & 155 & 4.6 & 2.185 & 3.35 & 400 & 360 & Dark brown \\
\hline 15 & 256 & 2.9 & 2.185 & 7.0 & 12 & 750 & Black \\
\hline 16 & 254 & 12.7 & 2.185 & 8.45 & 12 & 900 & Black \\
\hline 17 & 183 & 9.8 & 2.185 & 6.6 & 240 & 700 & Brown-black \\
\hline 18 & 133 & 21.5 & 11.485 & 15.2 & 69 & 400 & Brown \\
\hline 19 & 100 & 20.5 & 11.485 & 12.8 & 80 & 330 & Dark red-brown \\
\hline 20 & 100 & 23.2 & 11.485 & 12.7 & 35 & 330 & Dark red-brown \\
\hline 21 & 99 & 10.3 & 11.485 & 9.8 & 40 & 260 & Red-brown \\
\hline 22 & 77 & 18.7 & 11.485 & 9.2 & 175 & 240 & Orange-red \\
\hline 23 & 135 & 16.2 & 11.485 & 23.8 & 90 & 620 & Black \\
\hline 24 & 68 & 19.2 & 11.485 & 9.6 & 830 & 250 & Red-brown \\
\hline 25 & 70 & 14.4 & 11.485 & 5.7 & 1300 & 150 & Orange \\
\hline 26 & 120 & 12.8 & 11.485 & 9.7 & 25 & 250 & Red-brown \\
\hline $27^{\mathrm{e}}$ & 112 & 12.6 & 11.485 & 8.8 & 75 & 230 & Brown-black \\
\hline $28^{\circ}$ & 128 & 10.5 & 11.485 & 8.8 & 60 & 230 & Brown-black \\
\hline 30 & 229 & 8.3 & 1.671 & 13.8 & 7.5 & 2500 & Black \\
\hline
\end{tabular}

a Weight of $\mathrm{O}_{2}$ calculated from weight of $\mathrm{H}_{2} \mathrm{O}$ recovered upon hydrogenation.

b Assuming a constant specific surface area of $500 \mathrm{~cm}^{2} / \mathrm{g}$ for the copper. - Electrolytic oxygen used.

The appearance of the specimen may possibly give some indication of the extent of cupric oxide formation. It is of interest to note that Dighton and Miley ${ }^{20}$ were able to measure the effective contribution of each of the oxides, $\mathrm{Cu}_{2} \mathrm{O}$ and $\mathrm{CuO}$, to the total film thickness. For one particular film formed at $180^{\circ} \mathrm{C}$ the ratio $\mathrm{Cu}_{2} \mathrm{O}$ to $\mathrm{CuO}$ was $770 \mathrm{~A} / 48 \mathrm{~A}=16.0$; for one produced at $221^{\circ} \mathrm{C}$ the same ratio was $2000 / 122=16.4$. Even in the worst case of a film produced at $277^{\circ} \mathrm{C}$ the ratio was $5983 / 1016$ $=5.9$; it is believed therefore that in the present work the films consisted primarily of cuprous oxide even though the dark appearance of cupric oxide was observed for several of the thicker films.

For most of the experiments, carried out at temperatures below $250^{\circ} \mathrm{C}$, the oxidation curves were not parabolic. Log-log plots showed that many of the curves followed the cubic law approximately. It appeared that the condition of the sample, affected by the treatment during a given run, seriously influenced the course of the oxidation in the subsequent run. Evans ${ }^{21}$ has discussed the influence of physical factors upon the rate laws; such behavior for the irregular porous samples used is not unexpected.

The procedure for the measurement of the isotopic fractionation has been outlined in the previous section. Table II summarizes the $\mathrm{O}^{18}$ fractionation data. Examination of the data revealed no systematic dependence of $\alpha$ upon the pressure over the range of pressures investigated. All points were therefore plotted on the same graph in Fig. 1, which shows the dependence of $\alpha$ upon the reciprocal of the absolute temperature. The solid line represents the least-squares fit to the data. The

${ }^{20}$ A. L. Dighton and H. A. Miley, Trans. Electrochem. Soc. 81, 321 (1942).

${ }^{21}$ U. R. Evans, Trans. Electrochem. Soc. 91, 547 (1947). fractionation factors for experiments performed with the electrolytic oxygen, of low $\mathrm{O}^{18}$ content, are seen to agree quite well with the rest of the results.

The average deviation of all the points from the line is \pm 0.0020 , which is slightly greater than that anticipated on the basis of the analytical imprecision. The dotted line in Fig. 1 has been drawn through the data to extrapolate to an $\alpha$ of unity at $1 / T=0$. The slope is 8.5 $\mathrm{deg}^{-1}$, corresponding to an apparent activation energy of $17 \mathrm{cal} / \mathrm{mole}$. The average deviation of the points with respect to this line is \pm 0.0022 . Both lines pass through the point $\alpha=1.020$ at $150^{\circ} \mathrm{C}$.

Four additional experiments were carried out at considerably higher temperatures $\left(300-400^{\circ} \mathrm{C}\right)$, where quite thick films were formed in very short times $(<2 \mathrm{~min})$. Because of the extremely high rate of oxygen consumption and the inadequacy of mixing in the reaction chamber the local oxygen isotopic composition in the region of the metal was probably not maintained that of the bulk of the oxygen supply. These results are therefore of very doubtful validity. The enrichment values obtained under these conditions were less than the experimental uncertainty of $\pm 0.2 \%$. It is planned to do further work in the high temperature region with a modified apparatus.

Several auxiliary isotope exchange experiments were performed, in which it was found that there was negligible $\mathrm{O}^{18}$ exchange between gaseous oxygen and bulk cupric oxide (wire) at $400^{\circ} \mathrm{C}$ (in agreement with the results of Allen and Lauder. ${ }^{22}$ ) Winter and coworkers ${ }^{23}$ also showed, for a variety of metal oxides, that after the exchange of the first few surface layers of oxide the rate becomes extremely slow. Winter ${ }^{24}$ also investigated the exchange of oxygen-18 with the growing

TABLE II. Summary of $\mathrm{O}^{18}$ fractionation data.

\begin{tabular}{lcccc}
\hline \hline $\begin{array}{l}\text { Run } \\
\text { No. }\end{array}$ & $T\left({ }^{\circ} \mathrm{C}\right)$ & $f$ & $\epsilon$ & $\alpha$ \\
\hline 24 & 68 & 0.042 & 0.0197 & 1.0201 \\
25 & 70 & 0.036 & 0.0231 & 1.0235 \\
22 & 77 & 0.036 & 0.0198 & 1.0202 \\
21 & 99 & 0.061 & 0.0237 & 1.0244 \\
19 & 100 & 0.046 & 0.0215 & 1.0220 \\
20 & 100 & 0.034 & 0.0220 & 1.0224 \\
$27^{*}$ & 112 & 0.055 & 0.0188 & 1.0193 \\
26 & 120 & 0.059 & 0.0185 & 1.0190 \\
$28^{*}$ & 128 & 0.063 & 0.0179 & 1.0185 \\
18 & 133 & 0.048 & 0.0190 & 1.0195 \\
23 & 135 & 0.129 & 0.0208 & 1.0221 \\
13 & 155 & 0.040 & 0.0249 & 1.0254 \\
14 & 155 & 0.054 & 0.0174 & 1.0179 \\
17 & 183 & 0.063 & 0.0225 & 1.0232 \\
12 & 201 & 0.40 & 0.0169 & 1.0217 \\
11 & 203 & 0.066 & 0.0185 & 1.0191 \\
30 & 229 & 0.11 & 0.0155 & 1.0163 \\
16 & 254 & 0.061 & 0.0152 & 1.0157 \\
15 & 256 & 0.24 & 0.0154 & 1.0176
\end{tabular}

* Electrolytic oxygen used.

${ }^{22}$ J. A. Allen and I. Lauder, Nature 164, 142 (1949).

${ }^{23} \mathrm{G}$. Houghton and E. R. Winter, Nature 164, 1130 (1949); E. R. Winter, J. Chem. Soc. 1950, 1170.

${ }^{24}$ E. R. Winter, J. Chem. Soc. 1954, 3342. 
FIG. 1. Temperature dependence of the $\mathrm{O}^{18}$ fractionation factor in the reaction of oxygen with copper. O Purified tank oxygen. - Electrolytic oxygen. Least-squares line through data. Line extrapolating to $\alpha=1$ at $1 / T=0$

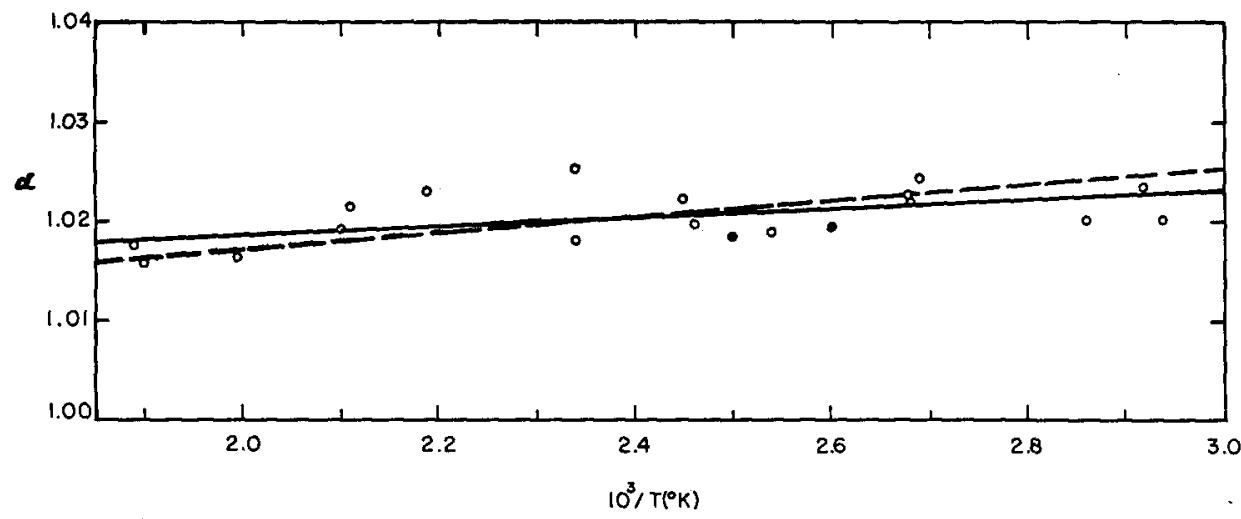

cuprous oxide film on copper at $50-110^{\circ} \mathrm{C}$ and pressures of $3 \mathrm{~cm}$ and found negligible exchange.

\section{DISCUSSION}

It is of interest to compare the fractionation factors obtained in the present investigation with the results of Dole and Lane ${ }^{10}$ for the chemisorption of oxygen on copper at room temperature. Extrapolation of the dotted line of Fig. 1 to $25^{\circ} \mathrm{C}$ gives as an upper limit the value $\alpha=1.029$, which is significantly lower than the fractionation factor of 1.05 found by these authors. ${ }^{25}$ The mechanism of the low temperature, very thin film chemisorption reaction is, of course, thought to be quite different than that associated with the formation of the films of intermediate thickness at elevated temperatures. Rhodin ${ }^{3}$ was able to demonstrate for copper the transition at $80^{\circ} \mathrm{C}$ from the thin film (low temperature), logarithmic law to the intermediate thickness, cubic law of oxidation.

Any satisfactory explanation of the $\mathrm{O}^{18}$ fractionation data should therefore account for the following qualitative observations:

(1) The direction of the fractionation is such that $\mathrm{O}^{16}$ tends to concentrate in the oxide film.

(2) The fractionation factor appears to be essentially independent of pressure (for pressures exceeding a few $\mathrm{cm} \mathrm{Hg}$.

(3) The fractionation factor appears to be independent of the extent of oxide film formation in the intermediate thickness range $(150-2500 \mathrm{~A})$.

(4) The isotope effect for the chemisorption reaction is apparently larger than that associated with the formation of films of intermediate thickness.

Cuprous oxide is known to be a metal-deficit semiconductor. The oxidation theory of Cabrera and Mott ${ }^{5}$ applied to the intermediate film thickness region makes use of the assumption that the cation transport (and thus the oxidation rate) is proportional to the number of cation vacancies $/ \mathrm{cm}^{3}, n_{i}$, and the strength of the electrostatic field, $F$, established by the oxygen ions

\footnotetext{
${ }^{25} \mathrm{M}$. Dole, private communication, in which a more recent corrected value of $\alpha$ is given for the reaction of oxygen with copper at room temperature.
}

located at the oxide-oxygen interface. The field strength is, of course, $V / X$, where $X$ is the oxide film thickness and $V$ is the electrostatic potential set up across the oxide film; $V$ is assumed independent of $X$. It is further hypothesized that the density of cation vacancies is proportional to the surface density of oxygen ions, $N$, which in turn is proportional to the field strength. Thus the oxidation rate, $d X / d t$, is found to be proportional to $F^{2}$ and is thus inversely proportional to $X^{2}$, in accord with the cubic law of oxidation. Here the rate should be independent of the oxygen pressure provided the surface is saturated with adsorbed oxygen.

According to this picture the isotopic composition of the oxide film would be identical with that of the surface layer of oxide ions. Any observed fractionation of $\mathrm{O}^{18}$ in the oxide would therefore reflect the fractionation associated with one of the possible steps in the establishment of the $\mathrm{O}^{=}$layer:

$$
\begin{aligned}
& \text { (1) } \mathrm{O}_{2}(\mathrm{~g}) \rightleftharpoons \mathrm{O}_{2} \text { (ads) } \\
& \text { (2) } \mathrm{O}_{2} \text { (ads) } \rightleftharpoons 2 \mathrm{O} \text { (ads) } \\
& \text { (3) } \mathrm{O}_{2} \text { (ads) }+4 e^{-} \rightarrow 2 \mathrm{O}^{=}= \\
& \text {(4) } \mathrm{O} \text { (ads) }+2 e^{-} \rightarrow \mathrm{O}^{=} .
\end{aligned}
$$

Since little or no isotopic fractionation would be associated with steps (1) $\ddagger$ and (4) (the $\mathrm{O}-\mathrm{O}$ bond is not ruptured), attention will be primarily centered on (2) and (3).

Winter' ${ }^{24}$ results, which indicated no exchange between $\mathrm{O}_{2}(g)$ and the growing film of cuprous oxide, suggest strongly that steps 3 and/or 4 are essentially irreversible (as indicated). His additional observation that the exchange reaction $\mathrm{O}_{2}{ }^{16}+\mathrm{O}_{2}{ }^{18} \rightleftharpoons 2 \mathrm{O}^{16} \mathrm{O}^{18}$ does not occur in the course of the oxidation implies that the dissociative adsorption of oxygen on cuprous oxide under the conditions of his experiments is an irreversible process. Winter concurs with the mechanism of Garner et $a .^{26}$ and writes the slow step:

$$
\mathrm{O}_{2}(\mathrm{~g})+2 \mathrm{Cu}^{+} \rightarrow 2 \mathrm{O}^{-}(\mathrm{ads})+2 \mathrm{Cu}^{++},
$$

$\ddagger$ For the equilibrium between gaseous and adsorbed $\mathrm{O}_{2}$ molecules one anticipates a slight $(<0.3 \%) \mathrm{O}^{18}$ enrichment in the adsorbed layer (based on the analogy with isotopic vapor pressure ratios).

${ }^{26}$ Garner, Stone, and Tiley, Proc. Roy Soc. (London) A211, 472 (1952). 
followed by rapid changes including the gain of an electron by $\mathrm{O}^{-}$, etc. Unfortunately this appears to be incompatible with the Cabrera-Mott concept of a quasiequilibrium involving adsorbed atomic oxygen and oxygen ions, which is essential to the derivation of the cubic law of oxidation. Actually, this may be explained if one notes that the actual rate law observed by Winter (using very finely divided copper powder) was of the exponential type, $p / p o=\exp (-k t)$, rather than cubic. This kinetic behavior was first noted by Wilkins and Rideal, ${ }^{27}$ at pressures below about $1 \mathrm{~cm}$. Experiments of Garner et al. ${ }^{26,28}$ with finely divided cuprous oxide powder showed that the rate of adsorption of oxygen (at low pressures) was proportional to the oxygen pressure. Thus the mechanism of Winter is self-consistent, but may not be relevant for the case of the usual cubic law oxidations carried out at moderate pressures.

Considering first the situation corresponding to the mechanism of Winter it is of interest to estimate the magnitude of the isotope effect for reaction of Eq. (8). Using the theory of Bigeleisen ${ }^{29}$ the ratio of the isotopic rate constants for $\mathrm{O}_{2}{ }^{16}$ and $\mathrm{O}^{16} \mathrm{O}^{18}$ would be

$$
\alpha=\frac{k}{k^{*}}=\left(\frac{m^{*}}{m}\right)^{\frac{1}{2}}(1+\delta)
$$

where

$$
\delta=\sum G(u) \Delta u-\sum G\left(u^{\ddagger}\right) \Delta u^{\ddagger},
$$

$m^{*} / m$ is the Slater ${ }^{30}$ reduced mass ratio and the other quantities have their usual significance. The lower limit of $\alpha$ (corresponding to $T \rightarrow \infty$ ) is thus the Slater factor, calculated to be 1.029. The upper limit, calculated in the usual way for the case of the free atom activated complex is $\alpha=1.080$ at $150^{\circ} \mathrm{C}$. Since the observed fractionation at $150^{\circ}$ lies well below the lower limit, this mechanism would seem to be eliminated. It should be noted however, that the high value of $\alpha$ obtained by Dole ${ }^{25}$ may well be associated with this type of mechanism.

Next consider the fractionation associated with the isotopic exchange equilibrium between gaseous oxygen molecules and adsorbed oxygen atoms. The upper limit for the fractionation factor may be readily calculated from an examination of the case of equilibrium between gaseous oxygen molecules and free atoms:

$$
\mathrm{O}_{2}{ }^{16}(\mathrm{~g})+\mathrm{O}^{18}(\mathrm{~g}) \rightleftharpoons \mathrm{O}^{16} \mathrm{O}^{18}(\mathrm{~g})+\mathrm{O}^{16}(\mathrm{~g}) .
$$

${ }^{27}$ F. J. Wilkins and E. K. Rideal, Proc. Roy. Soc. (London) A128, 394 (1930).

${ }_{28}$ Garner, Gray, Stone, Savage, and Tiley, Disc. Faraday Soc. 8, $246(1950)$.

${ }^{29}$ J. Bigeleisen, J. Chem. Phys. 17, 675 (1949).

${ }^{30}$ N. B. Slater, Proc. Roy. Soc. (London) A194, 112 (1948).
The method of calculation is given by Bigeleisen and Mayer ${ }^{31}$ and Urey. ${ }^{32}$ Assuming $\nu\left(\mathrm{O}^{16}-\mathrm{O}^{16}\right)=1580 \mathrm{~cm}^{-1}$ and $\Delta \nu=45 \mathrm{~cm}^{-1}$ one obtains the value $\alpha=1.050$ at $150^{\circ} \mathrm{C}$. This result is consistent with the value of the appropriate partition function ratio $\left(Q_{2} / Q_{1}\right)$ listed in Table $\mathrm{X}$ of reference 32. It may be of interest to compare the apparent activation energy for the fractionation factor, $17 \mathrm{cal} / \mathrm{mole}$, with the theoretical upper limit as given by the isotopic zero point energy difference (for $\mathrm{O}_{2}{ }^{16}$ and $\mathrm{O}^{16} \mathrm{O}^{18}$ ) of $64 \mathrm{cal} / \mathrm{mole}$.

For the adsorption-exchange reaction:

$$
\mathrm{O}_{2}{ }^{16}(\mathrm{~g})+\mathrm{O}^{18}-\mathrm{S} \rightleftharpoons \mathrm{O}^{16} \mathrm{O}^{18}(\mathrm{~g})+\mathrm{O}^{16}-\mathrm{S},
$$

(where $S$ represents an adsorption site), it is not possible to calculate the fractionation factor without some assumption as to the $\mathrm{O}^{16}-S$ force constant or vibration frequency. However, by inverting the procedure, it is possible to estimate the frequency which would be required to account for the observed value of $\alpha=1.020$ \pm 0.002 at $150^{\circ} \mathrm{C}$. This was done, first, by assuming the ratio $\Delta \nu / \nu=0.029$ (equivalent to an effective mass $\left.m_{s}=16 \mathrm{awu}\right)$. This gives a value for $\nu\left(\mathrm{O}^{16}-S\right)$ of 1150 $\pm 50 \mathrm{~cm}^{-1}$. The other extreme case, assuming $\Delta \nu / \nu$ $=0.061$ (equivalent to an effective mass $m_{s}=\infty$ ) gives the result $\nu\left(\mathrm{O}^{16}-S\right)=780 \pm 25 \mathrm{~cm}^{-1}$. The actual frequency would then be expected to lie within the range $780-1150 \mathrm{~cm}^{-1}$, which does not seem implausible.

It is therefore suggested on the basis of the present results that the mechanism of the $\mathrm{O}^{18}$ fractionation observed in the oxidation of copper (under the conditions of these experiments) involves the isotopic exchange equilibrium between gaseous oxygen molecules and chemisorbed oxygen atomsई which favors the concentration of $\mathrm{O}^{16}$ in the adsorbed layer. Then, in accord with the assumptions inherent in the Cabrera-Mott theory, it is expected that the isotopic composition of the oxide will be the same as that of the adsorbed layer. This interpretation appears to be consistent with the present observations.

\section{ACKNOWLEDGMENTS}

The author is grateful for financial assistance received from the following sources: (a) Michigan MemorialPhoenix Project No. 78, (b) DuPont Grant for Fundamental Research in Chemistry, and (c) U. S. Atomic Energy Commission, Contract AT(11-1)-321.

31 J. Bigeleisen and M. G. Mayer, J. Chem. Phys. 15, 261 (1947).

${ }^{32}$ H. C. Urey, J. Chem. Soc. $1947,562$.

$\$$ It should be pointed out that this exchange mechanism is not supported by the (low-pressure) experiments of Winter, ${ }^{24}$ as previously discussed. 